\title{
Manufacturing of Silica Glass from Silica Powder Consolidated with Tetramethoxysilane Oligomer-derived Binder (II). Role of Tetramethylammonium Hydroxide as a Catalyst for Binder Synthesis
}

\author{
Osamu YAGI \\ Chouetsushi Laboratory, Kazari-ichi Co., Ltd. (Room no. F, Sangaku Kyodo Kenkyu Center, 1-1-2 Suehiro-Cho, \\ Tsurumi-ku, Yokohama, Kanagawa 230-0051, Japan)
}

Received November 25, 2002 ; Accepted June 19, 2003

\begin{abstract}
The role of a catalyst during the synthesis of a binder, which could harden a silica slurry, was investigated. Tetramethoxysilane oligomer was efficiently hydrolyzed and poly-condensed to the binder when tetramethylammonium hydroxide and tetraethylammonium hydroxide, which are both organic bases having bulky groups, were used as catalysts. On the other hand, nitric acid, sodium hydroxide, potassium hydroxide and ammonia were not effective catalysts for binder synthesis. The difference in the role between these catalysts was explained as follows. The bulky organic groups were assumed to have a steric hindrance interaction with methyl groups in tetramethoxysilane oligomer and this steric interaction could successfully produce the binder.
\end{abstract}

Key Words : Sol-gel Method, Silica Glass, Tetramethylammonium Hydroxide, Tetramethoxysilane

\section{Introduction}

Silica glass is one of the most important materials for semiconductor manufacturing, because it has a high melting point and a small amount of metallic impurities. The general method to make silica glass is to melt natural quartz. However, natural quartz contains a large amount of metallic impurities such as $\mathrm{Al}$ and Ti. Highly purified silica glass has been manufactured by the sol-gel method. ${ }^{1,2)}$ When using this method, however, the green compact must shrink, which leads to many cracks during the drying process. ${ }^{3}$ Toki et al ${ }^{4}$ ) used colloidal silica to prevent the shrinkage. This method was very useful in reducing the shrinkage, however, precipitation of colloidal silica took place when the sol solution stood for a long time, generating many cracks during the drying process.

Previously, the author described a new method ${ }^{5)}$ for the effective and inexpensive manufacturing of purified silica glass in which the hardening of a slurry of a purified synthetic silica powder with a binder had been applied to prevent cracking of the silica bulk during the drying process and then the bulk was successfully sintered to produce the silica glass. This method is characterized by the flexibility of the binder. The methoxysilane oligomer (MS-51) used in the binder synthesis was incompletely hydrolyzed and poly-condensed, leaving partial methoxy groups in the binder, which provided flexibility to the binder. Moreover, tetramethylammonium hydroxide (TMAH), ${ }^{6}$ ' which is an organic base having a bulky group, was a good catalyst for the binder synthesis.

In this paper, the role of TMAH as the catalyst for the synthesis of binder in manufacturing the bulk by hardening a slurry of silica powder was described.

\section{1 Materials}

\section{Experimental}

Methanol and ethanol were both distilled from the extra pure grade reagents (Kanto Chemical Co., Inc.) and stored in polyethylene bottles. Ethylene glycol, nitric acid and ammonia water (special grade reagents both from Kanto Chemical Co., Inc.) were used without further purification. The oligomer of tetramethoxysilane (MS-51; trimer as the mean polymerization degree), tetramethylammonium hydroxide (TMAH) solution and tetraethylammonium hydroxide (TEAH) solution were made by Tama Chemicals Co., Ltd. The silica powder $(20 \mu \mathrm{m}$ mean diameter) was made by Mitsubishi Rayon Co., Ltd.

\section{2 Measurement of the slurry hardening time}

In a $500 \mathrm{ml}$ three-necked glass vessel with a thermometer and a condenser, $218.4 \mathrm{~g}$ of MS-51 and $80 \mathrm{~g}$ of methanol were added and stirred, and then $21.6 \mathrm{~g}$ of an aqueous solution including the catalyst for the binder synthesis was added. The reaction mixture was heated in an oil bath. The silica slurry was made by mixing $64.2 \mathrm{~g}$ of the reaction mixture with $22.0 \mathrm{~g}$ of ethanol and $20.0 \mathrm{~g}$ of ethylene glycol in a polyethylene vessel, and then stirred with $250 \mathrm{~g}$ of the silica powder. After $1.7 \mathrm{~g}$ of a slurry hardening catalyst was added to the silica slurry which was then stirred for $4 \mathrm{~min}$, it was poured into a polypropylene container which was covered with a polyethylene sheet. The slurry hardening time is defined as the course of reaction time for the slurry to harden enough so that it did not flow when the container was slanted.

2. 3 Influence of acid concentration of the binder on dried bulk synthesis

In the same $500 \mathrm{ml}$ three-necked glass vessel as described above, $218.4 \mathrm{~g}$ of MS-51 and $80 \mathrm{~g}$ of methanol 
Table 1 Measurement of the slurry hardening time on bulk synthesis.

\begin{tabular}{|c|c|c|c|c|c|c|c|c|}
\hline \multirow{2}{*}{ Run } & \multirow{2}{*}{$\begin{array}{c}\text { MS-51 } \\
\mathrm{g}\end{array}$} & \multicolumn{2}{|r|}{$\mathrm{H}_{2} \mathrm{O}^{\mathrm{a})}$} & \multirow{2}{*}{$\begin{array}{c}\text { Methanol } \\
\mathrm{g}\end{array}$} & \multirow{2}{*}{$\begin{array}{c}\text { Time }^{\mathrm{c})} \\
\mathrm{h}\end{array}$} & \multirow{2}{*}{$\begin{array}{c}\text { Binder } \\
\text { catalyst }\end{array}$} & \multirow{2}{*}{$\begin{array}{c}\text { Hardening } \\
\text { catalyst }\end{array}$} & \multirow{2}{*}{$\begin{array}{c}\text { Hardening } \\
\text { Time }\end{array}$} \\
\hline & & $\mathrm{g}$ & equivalentb) & & & & & \\
\hline 1 & 218.4 & 21.6 & 2.0 & 80 & 16 & $\mathrm{HNO}_{3}\left(3.17 \times 10^{-2} \mathrm{~mol} \mathrm{dm}-3\right)$ & $\mathrm{HNO}_{3}\left(3.17 \times 10^{-2} \mathrm{~mol} \mathrm{dm}-3\right)$ & $>2 \mathrm{~h}$ \\
\hline 2 & 218.4 & 21.6 & 2.0 & 80 & 16 & $\mathrm{HNO}_{3}\left(3.17 \times 10^{-2} \mathrm{~mol} \mathrm{dm}-3\right)$ & TMAH $\left(1.10 \times 10^{-1} \mathrm{~mol} \mathrm{dm}^{-3}\right)$ & $>2 \mathrm{~h}$ \\
\hline 3 & 218.4 & 21.6 & 2.0 & 80 & 16 & $\mathrm{HNO}_{3}\left(3.17 \times 10^{-2} \mathrm{~mol} \mathrm{dm}^{-3}\right)$ & $\mathrm{NH}_{4} \mathrm{OH}\left(2.86 \times 10^{-1} \mathrm{~mol} \mathrm{dm}^{-3}\right)$ & $<1 \mathrm{mim}$ \\
\hline 4 & 218.4 & 21.6 & 2.0 & 80 & 2 & $\mathrm{HNO}_{3}\left(3.17 \times 10^{-2} \mathrm{~mol} \mathrm{dm}^{-3}\right)$ & $\mathrm{NH}_{4} \mathrm{OH}\left(2.86 \times 10^{-1} \mathrm{~mol} \mathrm{dm}^{-3}\right)$ & $<1 \min$ \\
\hline 5 & 218.4 & 21.6 & 2.0 & 80 & $<0.5$ & $\mathrm{NH}_{4} \mathrm{OH}\left(2.86 \times 10^{-2} \mathrm{~mol} \mathrm{dm}^{-3}\right)$ & - & gelation \\
\hline 6 & 218.4 & 21.6 & 2.0 & 80 & 2 & TMAH $\left(1.10 \times 10^{-2} \mathrm{~mol} \mathrm{dm}^{-3}\right)$ & $\mathrm{HNO}_{3}\left(3.17 \times 10^{-2} \mathrm{~mol} \mathrm{dm}{ }^{-3}\right)$ & $>2 \mathrm{~h}$ \\
\hline 7 & 218.4 & 21.6 & 2.0 & 80 & 2 & TMAH $\left(1.10 \times 10^{-2} \mathrm{~mol} \mathrm{dm}^{-3}\right)$ & TMAH $\left(1.10 \times 10^{-1} \mathrm{~mol} \mathrm{dm}^{-3}\right)$ & $>2 \mathrm{~h}$ \\
\hline 8 & 218.4 & 21.6 & 2.0 & 80 & 2 & TMAH $\left(1.10 \times 10^{-2} \mathrm{~mol} \mathrm{dm}^{-3}\right)$ & $\mathrm{NH}_{4} \mathrm{OH}\left(2.86 \times 10^{-1} \mathrm{~mol} \mathrm{dm}^{-3}\right)$ & $15 \mathrm{~min}$ \\
\hline
\end{tabular}

a) Water content in the binder. b) Mole equivalent to the methoxy groups in MS-51. ${ }^{\text {c) }}$ Refluxing time.

Table 2 Influence of the residual acid concentration of the binder on dried bulk synthesis.

\begin{tabular}{|c|c|c|c|c|c|}
\hline Run & $\begin{array}{c}\text { Acid conc. of } \\
\text { MS-51 (mg/g) }\end{array}$ & $\begin{array}{l}\text { Binder } \\
\text { catalyst }\end{array}$ & $\begin{array}{l}\text { Total acid conc. } \\
\text { of binder }(\mathrm{mg} / \mathrm{g})\end{array}$ & $\underset{\mathrm{h}}{\mathrm{Time}}$ & Result ${ }^{b)}$ \\
\hline 1 & 0.027 & $\mathrm{HNO}_{3}\left(3.17 \times 10^{-2} \mathrm{~mol} \mathrm{dm}^{-3}\right)$ & 0.110 & 2 & Many long cracks \\
\hline 2 & 0.027 & $\mathrm{HNO}_{3}\left(3.17 \times 10^{-2} \mathrm{~mol} \mathrm{dm}^{-3}\right)$ & 0.110 & 19 & Many long cracks \\
\hline 3 & 0.027 & $\mathrm{HNO}_{3}\left(1.59 \times 10^{-2} \mathrm{~mol} \mathrm{dm}^{-3}\right)$ & 0.064 & 2 & Many long cracks \\
\hline 4 & 0.027 & $\mathrm{HNO}_{3}\left(1.59 \times 10^{-2} \mathrm{~mol} \mathrm{dm}^{-3}\right)$ & 0.064 & 19 & Many long cracks \\
\hline 5 & 0.041 & - & 0.028 & 6 & One or two short cracks \\
\hline 6 & 0.041 & TMAH $\left(5.48 \times 10^{-3} \mathrm{~mol} \mathrm{dm}^{-3}\right)$ & 0.013 & 7 & No crack \\
\hline 7 & 0.041 & TMAH $\left(1.10 \times 10^{-2} \mathrm{~mol} \mathrm{dm}^{-3}\right)$ & -0.003 & 2 & No crack \\
\hline 8 & 0.041 & TMAH $\left(1.65 \times 10^{-2} \mathrm{~mol} \mathrm{dm}^{-3}\right)$ & -0.019 & 1 & One or two short cracks \\
\hline 9 & 0.041 & TMAH $\left(1.65 \times 10^{-2} \mathrm{~mol} \mathrm{dm}^{-3}\right)$ & -0.019 & 2 & Many long cracks \\
\hline 10 & 0.027 & $\mathrm{NH}_{4} \mathrm{OH}\left(1.43 \times 10^{-3} \mathrm{~mol} \mathrm{dm}^{-3}\right)$ & 0.015 & 3 & One or two short cracks \\
\hline 11 & 0.027 & $\mathrm{NH}_{4} \mathrm{OH}\left(2.86 \times 10^{-3} \mathrm{~mol} \mathrm{dm}^{-3}\right)$ & 0.011 & 2 & Many long cracks \\
\hline 12 & 0.027 & $\mathrm{NH}_{4} \mathrm{OH}\left(5.71 \times 10^{-3} \mathrm{~mol} \mathrm{dm}^{-3}\right)$ & 0.002 & 3.5 & Gelation after 3 days \\
\hline 13 & 0.027 & $\mathrm{NH}_{4} \mathrm{OH}\left(1.43 \times 10^{-2} \mathrm{~mol} \mathrm{dm}^{-3}\right)$ & -0.022 & 1.5 & Gelation \\
\hline 14 & 0.027 & $\mathrm{NH}_{4} \mathrm{OH}\left(2.86 \times 10^{-2} \mathrm{~mol} \mathrm{dm}^{-3}\right)$ & -0.064 & 0.5 & Gelation \\
\hline
\end{tabular}

a) The different residual acid concentrations of MS-51 are due to the samples which have different batchs of MS-51 preparation. b) Short crack: less than $10 \mathrm{~mm}$ depth, long crack: more than $10 \mathrm{~mm}$ depth.

were added and stirred, and then $21.6 \mathrm{~g}$ of the catalyst solution was added. The reaction mixture was heated in an oil bath. After cooling, $64.2 \mathrm{~g}$ of the reaction mixture was added to ethanol and ethylene glycol in a polyethylene vessel, and then stirred with $250 \mathrm{~g}$ of the silica powder. The slurry was mixed with $1.7 \mathrm{~g}$ of a $\mathrm{NH}_{4} \mathrm{OH}(5.71$ $\times 10^{-1} \mathrm{~mol} \mathrm{dm}^{-3}$ ) solution and stirred for $4 \mathrm{~min}$. It was then poured into a 105- $\mathrm{mm}$ diameter mold and covered. After $3 \mathrm{~h}$, the hardened wet bulk was removed from the mold and put into a polyvinyl chloride bag. Five small holes of about $5 \mathrm{~mm}$ diameter each were made in it every $24 \mathrm{~h}$. The bulk, which was dried this way for 1 week, was then allowed to stand in open air. The presence of cracks was then investigated.

\section{Results and Discussion}

The slurry, which was mixed with the binder, silica powder and solvents, was poured into the polypropylene container, and the hardening time was measured from the time when its mobility was lost. The results are shown in Table 1 . When a $\mathrm{NH}_{4} \mathrm{OH}\left(2.86 \times 10^{-2} \mathrm{~mol}\right.$ $\mathrm{dm}^{-3}$ ) solution was used as the binder catalyst (Run 5), the binder gelled in the glass vessel. When combinations of the binder catalysts and hardening catalysts were $\mathrm{HNO}_{3}\left(3.17 \times 10^{-2} \mathrm{~mol} \mathrm{dm}{ }^{-3}\right) / \mathrm{HNO}_{3}\left(3.17 \times 10^{-2} \mathrm{~mol}\right.$ $\left.\mathrm{dm}^{-3}\right)$ (Run 1), $\mathrm{HNO}_{3}\left(3.17 \times 10^{-2} \mathrm{~mol} \mathrm{dm}{ }^{-3}\right) / \mathrm{TMAH}$ $\left(1.10 \times 10^{-1} \mathrm{~mol} \mathrm{dm}^{-3}\right)$ (Run 2), TMAH $\left(1.10 \times 10^{-2} \mathrm{~mol}\right.$ $\left.\mathrm{dm}^{-3}\right) / \mathrm{HNO}_{3}\left(3.17 \times 10^{-2} \mathrm{~mol} \mathrm{dm}{ }^{-3}\right)$ (Run 6) and TMAH $\left(1.10 \times 10^{-2} \mathrm{~mol} \mathrm{dm}^{-3}\right) /$ TMAH $\left(1.10 \times 10^{-1} \mathrm{~mol} \mathrm{dm}^{-3}\right)$ (Run 7), the hardening times were over $2 \mathrm{~h}$. On the other hand, when the combination was $\mathrm{HNO}_{3}(3.17 \times$ $\left.10^{-2} \mathrm{~mol} \mathrm{dm}^{-3}\right) / \mathrm{NH}_{4} \mathrm{OH}\left(2.86 \times 10^{-1} \mathrm{~mol} \mathrm{dm}^{-3}\right.$ ) (Runs 3 and 4), the times were too short for handling. The most favorable one was TMAH $\left(1.10 \times 10^{-2} \mathrm{~mol} \mathrm{dm}^{-3}\right)$ as the binder catalyst and $\mathrm{NH}_{4} \mathrm{OH}\left(2.86 \times 10^{-1} \mathrm{~mol} \mathrm{dm}{ }^{-3}\right)$ as the hardening catalyst (Run 8 ). The reason why TMAH showed a good result as the binder catalyst is discussed as follows.

MS-51 used here usually contains a small amount of acid (nitric acid). When MS-51 is made from its monomer and water by a poly-condensation reaction, an acid catalyst (nitric acid) is used and consequently a small amount of it remains in MS-51. In this study, when MS51 is used as the starting material and the acid catalyst is added to the binder synthesis process, the total catalyst concentration in the binder solution is actually more acidic than what is added. When a basic catalyst is used, on the other hand, it is actually less acidic than what is added. The influence of the residual acid significantly appears for a small amount of catalyst. Therefore, the catalyst effect in synthesizing the binder was examined with the consideration of the residual acid in MS-51 (Table 2). 
In Table 2, the "acid conc. in MS-51: $0.027 \mathrm{mg} / \mathrm{g}$ " shows that $0.027 \mathrm{mg}$ of $\mathrm{KOH}$ was consumed for neutralizing the residual acid in $1 \mathrm{~g}$ of MS-51. The symbol "-." in the fourth column means that the binder was basic.

When nitric acid was used as the binder catalyst (Runs 1-4), the dry bulk, which had no cracks, was not able to be obtained regardless of the acid concentration. In the case of $\mathrm{NH}_{4} \mathrm{OH}$ as the catalyst, the obtained binder immediately gelled when its concentration was high. Only at a very low concentration of $1.43 \times 10^{-3} \mathrm{~mol} \mathrm{dm}^{-3}$, the dry bulk had "one or two short cracks" in it. In the case of TMAH as the catalyst, the good results were obtained at concentrations of less than $1.10 \times 10^{-2} \mathrm{~mol} \mathrm{dm}^{-3}$ (Runs 6 and 7). This means that better results for all catalyst used here were obtained when the acidities of the binders gradually approached neutral. Among them, the best result was obtained for TMAH which was able to be used over a wider concentration range than the others.

Generally, the catalysts used in the sol-gel method are acids and bases. There is, however, a significant difference between them in the mechanism of hydrolysis and poly-condensation. The difference in the mechanism for them is explained as follows. Steric factors exert the greatest effect on the hydrolytic stability of alkoxysilanes. An alkyl and a hydroxyl groups should increase the stability of the positive and negative charged transition states, respectively (Fig. 1) ${ }^{1}$. Under acidic conditions, the hydrolysis rate decreases with each subsequent hy-

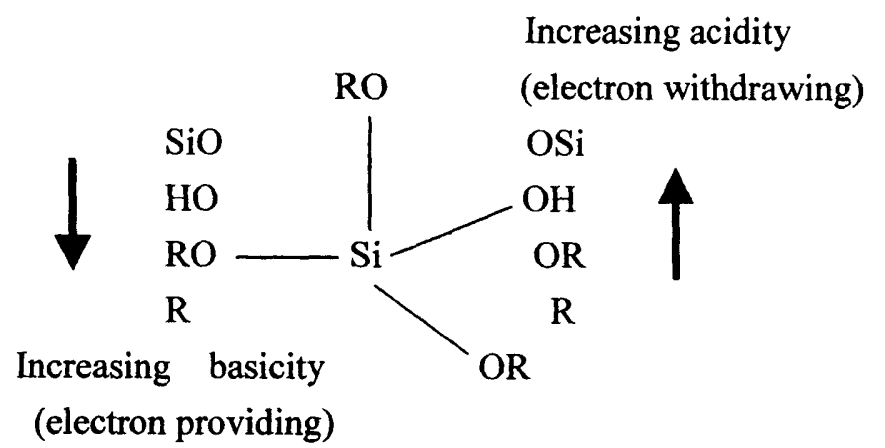

Fig. 1 Inductive effects of substituents bond to silicon, R, OR, OH or OSi. ${ }^{1)}$<smiles>[R2][Si]([R20])([R20])([R2])(O)O</smiles>

(a)<smiles>[R]O[Si]([R2])([R])([R20])([O])O</smiles>

(c)<smiles>[R][Si]([R20])([R20])([R20])([R2])O</smiles>

(b)<smiles>[R][Si]([R20])([R20])O[OH2+]</smiles>

(d)
Fig. 2 Hydrolysis mechanism of alkoxysilane. (a), (b); basic condition and (c), (d); acidic condition. drolysis step, whereas under basic conditions, the increased electron withdrawing capabilities of $\mathrm{OH}$ (and OSi) compared to OR may establish a condition in which each subsequent hydrolysis step occurs more quickly as the hydrolysis and condensation proceed.

In the case of basic conditions, when compared with the two compounds in Fig. 2 (a) and (b), it shows that the $\mathrm{Si}$ atom having an $\mathrm{OH}$ (or $\mathrm{SiO}$ ) group (Fig. 2 (a)) is easily attacked by $\mathrm{OH}^{-}$rather than one not having it (Fig. 2 (b)) because of their charges on the $\mathrm{Si}$ atoms $\left(\delta \mathrm{a}^{+}>\delta \mathrm{b}^{+}\right)$. This means that once the $\mathrm{Si}$ atom is attacked by $\mathrm{OH}^{-}$, an $\mathrm{RO}$ group is immediately replaced by an $\mathrm{OH}$ group which then poly-condensed to siloxane bonds and finally result in a particle which has a highly developed 3-dimensional structure.

In the case of acidic conditions, on the other hand, a hydrolysis reaction begins first by the addition of $\mathrm{H}^{+}$to the oxygen atom in the RO group (Fig. 2 (c) and (d)). This means that the $\mathrm{Si}$ atom once attacked by $\mathrm{OH}^{-}$(Fig. 2 (c)) does not receive further attack as there are some other $\mathrm{Si}$ atoms which have more RO groups (Fig. 2 (d)). That is, all molecules uniformly undergo the reactions of hydrolysis and poly-condensation. This attack is more favorable for the $\mathrm{Si}$ atom which has more RO groups than the others. Therefore, siloxane chains in the binder obtained under acidic conditions produce a thin film of which the microstructure will become more regular than under basic conditions. This is the reason why a thin film or a fiber will be obtained when acidic conditions are used.

This fact shows that acidic conditions are better than basic conditions for a binder catalyst. For this reason, an acid was thought to be better for a catalyst at the beginning of this study. In the case of nitric acid, in fact, good results could not be obtained when its concentrations were high (Table 2, Runs 1-4). When the condition of the binder solution was nearly neutral, "one or two shorts cracks" were observed in the dried bulk (Table 2, Run $5)$.

The reason why better results were obtained when the condition of the binder solution was nearly neutral was

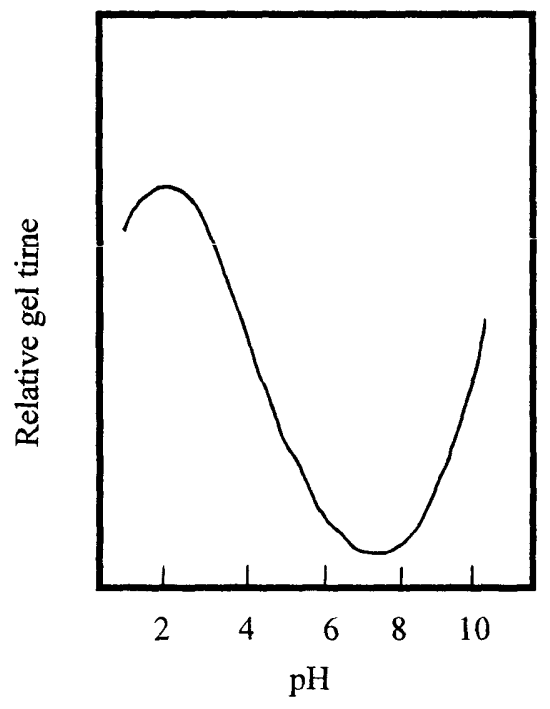

Fig. 3 Relative gel time. ${ }^{1)}$ 
Table 3 Influence of organic and inorganic catalysts on binder synthesis ${ }^{a}$.

\begin{tabular}{|c|c|c|c|c|c|c|c|}
\hline \multirow{2}{*}{ Run } & \multirow{2}{*}{$\begin{array}{c}\text { MS-51 } \\
\mathrm{g} \\
\end{array}$} & \multicolumn{2}{|r|}{$\mathrm{H}_{2} \mathrm{O}$} & \multirow{2}{*}{$\begin{array}{l}\text { Methanol } \\
\mathrm{g}\end{array}$} & \multirow{2}{*}{$\begin{array}{c}\text { Time }^{\mathrm{c})} \\
\mathrm{h}\end{array}$} & \multirow{2}{*}{$\begin{array}{l}\text { Binder } \\
\text { catalyst }\end{array}$} & \multirow{2}{*}{ Result } \\
\hline & & $\mathrm{g}$ & equivalent $t^{\text {b) }}$ & & & & \\
\hline 1 & 218.4 & 16.2 & 1.5 & 80 & 7 & TMAH $\left(5.5 \times 10^{-3} \mathrm{~mol} \mathrm{dm}^{-3}\right)$ & No crack \\
\hline 2 & 218.4 & 16.2 & 1.5 & 80 & 7 & TEAH $\left(5.5 \times 10^{-3} \mathrm{~mol} \mathrm{dm}^{-3}\right)$ & No crack \\
\hline 3 & 218.4 & 16.2 & 1.5 & 80 & 7 & $\mathrm{NaOH}\left(5.5 \times 10^{-3} \mathrm{~mol} \mathrm{dm}^{-3}\right)$ & Many cracks \\
\hline 4 & 218.4 & 16.2 & 1.5 & 80 & 7 & $\mathrm{KOH}\left(5.5 \times 10^{-3} \mathrm{~mol} \mathrm{dm}^{-3}\right)$ & Many cracks \\
\hline 5 & 218.4 & 16.2 & 1.5 & 80 & 1 & $\mathrm{NH}_{4} \mathrm{OH}\left(5.5 \times 10^{-3} \mathrm{~mol} \mathrm{dm}^{-3}\right)$ & gelation \\
\hline
\end{tabular}

a) Bulk was prepared with $\mathrm{SiO}_{2}$ powder $250 \mathrm{~g}$, the binder $64.2 \mathrm{~g}$, ethanol $22.0 \mathrm{~g}$ and ethylene glycol $20.0 \mathrm{~g}$, and was followed by addition of a $\mathrm{NH}_{4} \mathrm{OH}\left(5.71 \times 10^{-1} \mathrm{~mol} \mathrm{dm}^{-3}\right)$ solution $1.7 \mathrm{~g}$. b) Mole equivalent to the methoxy groups in MS-51. c) Refluxing time.

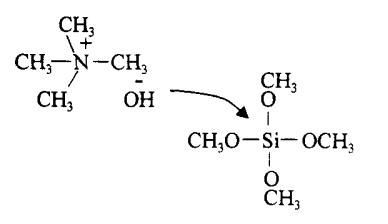

(a)

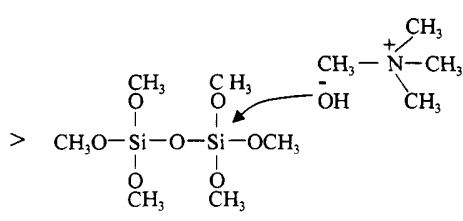

(b)
Fig. 4 Steric interaction between TMAH and alkoxysilane in hydrolysis.

considered as follows. The relationship between the $\mathrm{pH}$ value and the gelation time is shown in Fig. 3. ${ }^{1)}$ Under acidic conditions, the condensation reaction is dominated by Eq. (1) and Eq. (2). It takes a long time for alkoxysilane to polymerize, because Eq. (2) is a slow reaction.

$$
\begin{aligned}
& \equiv \mathrm{Si}-\mathrm{OH}+\mathrm{H}^{+} \longrightarrow \equiv \mathrm{Si}^{+} \mathrm{OH}_{2}{ }^{+} \\
& \equiv \mathrm{Si}-\mathrm{OH}_{2}{ }^{+}+\equiv \mathrm{Si}-\mathrm{OH} \rightarrow \equiv \mathrm{Si}-\mathrm{O}-\mathrm{Si} \equiv+\mathrm{H}_{3} \mathrm{O}^{+}
\end{aligned}
$$

Under basic conditions, the condensation reaction is dominated by Eq. (3), Eq. (4) and Eq. (5). In a high pH region, the generated polymer decomposes into a low molecule unit according to Eq. (5). Therefore, it also takes a long time for alkoxysilane to polymerize.

$$
\begin{aligned}
& \equiv \mathrm{Si}-\mathrm{OR}+{ }^{-} \mathrm{OH} \longrightarrow \equiv \mathrm{Si}^{-} \mathrm{O}^{-}+\mathrm{ROH} \\
& \equiv \mathrm{Si}-\mathrm{O}^{-}+\equiv \mathrm{Si}-\mathrm{OR} \longrightarrow \equiv \mathrm{Si}-\mathrm{O}-\mathrm{Si} \equiv+{ }^{-} \mathrm{OR} \\
& \equiv \mathrm{Si}-\mathrm{O}-\mathrm{Si} \equiv{ }^{-} \mathrm{OH} \longrightarrow \equiv \mathrm{Si}^{-} \mathrm{O}^{-}+\equiv \mathrm{Si}-\mathrm{OH}
\end{aligned}
$$

On the other hand, at near neutral pH, since Eq. (5) is not accelerated because of lower concentration of ${ }^{-} \mathrm{OH}$ than under basic conditions, the polymerization of alkoxysilane takes a short time. Therefore, the binder was obtained for a short reaction time at neutral $\mathrm{pH}$.

TMAH exhibited a higher catalytic ability for binder synthesis than the other catalysts (nitric acid and ammonia) when a binder was synthesized under nearly neutral condition. This fact is explained as follows. When TMAH is used as a catalyst, tetramethylammonium ion $\left(\mathrm{TMA}^{+}\right)$ having an organic property can be assumed to have a steric interaction with alkoxy groups of the alkoxysilane. The hydrolysis reaction of alkoxysilane is a $\mathrm{S}_{\mathrm{N}} 2$ mechanism $^{7}$ as shown in Eq. (6).

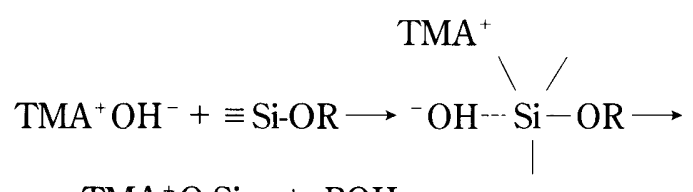$$
\mathrm{TMA}^{+} \mathrm{O}-\mathrm{Si} \equiv+\mathrm{ROH}
$$

Because the conjugate acid $\left(\mathrm{TMA}^{+}\right)$of ${ }^{-} \mathrm{OH}$ is bulky compared to $\mathrm{NH}_{4} \mathrm{OH}$, this reaction will be more affected by the steric interaction than using less bulky catalysts such as $\mathrm{NH}_{4} \mathrm{OH}$. This means that the $\mathrm{Si}$ atom once attached by $\mathrm{Si}^{-} \mathrm{O}^{-}$(Fig. 4 (b)) does not receive a further attack as there are some other $\mathrm{Si}$ atoms which have fewer Si groups (Fig. 4 (a)) than it. Namely, TMAH having bulky organic groups uniformly catalysts the polycondensation reaction the same as the acid type reaction. This interaction also affected the slurry hardening time. When using TMAH as a slurry hardening catalyst, its hardening times were far longer than the $\mathrm{NH}_{4} \mathrm{OH}$ catalyst (Table 1, Runs 2 and 3, and Runs 7 and 8).

In order to confirm the efficiency of the bulky organic bases as the catalyst, binders were synthesized with tetraethylammonium hydroxide (TEAH) as the bulky organic base and sodium hydroxide and potassium hydroxide as the less bulky inorganic bases. These results are shown in Table 3. For the organic bases, dried bulks could be obtained without cracks. For the inorganic bases, on the other hand, a bulk with no crack could not be obtained. These results suggest the difference in the catalytic mechanisms between the bulky organic and less bulky inorganic bases.

\section{Conclusion}

The effectiveness of TMAH as a catalyst of the binder synthesis when manufacturing a dried bulk was described. The bulky organic bases were assumed to exhibit the ability of the binder to make a dried bulk have no cracks during the drying process.

\section{References}

1) C. J. Brinker and G. W. Scherer, Sol-Gel Science, Academic Press Inc. (1990).

2) L. L. Hench and J. K. West, Chem. Rev., 90, 33 (1990).

3) F. Kirkbir, H. Murata, D. Meyers, S. R. Chaudhuri, and A. Sarkar, J. Sol-Gel Sci. Tech., 6, 203 (1996).

4) M. Toki, T. Takeuchi, S. Miyasita, and S. Kanbe, J. Mate. Sci., 27, 2857 (1992).

5) O. Yagi, Electrochemistry, 70, 270 (2002).

6) O. Yagi and S. Shimizu, Denki Kagaku (Presently Electrochemistry), 64, 225 (1996).

7) A. C. Pierre, Introduction to Sol-Gel Processing, Kluwer Academic Publishers. (1998). 